\title{
CLIMATE MODELLING: PREDICTING THE FUTURE OF THE PLANET
}

\begin{abstract}
THE EARTH'S CLIMATE IS CHANGING DUE TO GREENHOUSE GAS EMISSIONS RESULTING FROM HUMAN ACTIVITY. BEING ABLE TO PREDICT THESE CHANGES IS CRUCIAL FOR PREPARING FOR THEIR EFFECTS AND FOR PROVIDING THE MOTIVATION NEEDED TO REDUCE EMISSIONS. DR ALAN CONDRON OF THE WOODS HOLE OCEANOGRAPHIC INSTITUTION IS DEVELOPING SOME KEY CLIMATE MODELS TO BRING THESE PREDICTIONS INTO EXISTENCE
\end{abstract}

\section{TALK LIKE A GLIMATE MODELLER}

CLIMATE CHANGE - a change in regional or global climate patterns, generally caused by changes in the planet's atmospheric or ocean circulation. Many of the changes we predict will occur in the future are a result of increased greenhouse gases caused by humans burning fossils

ICE CORE - a cylinder of ice obtained by drilling down into an ice sheet or glacier. The layers of ice towards the bottom of the cylinder are older than those at the top and so their characteristics provide a record of the climate in the past

LATITUDE - the distance of a place from the equator, with $0^{\circ}$ beginning at the equator and $90^{\circ}$ the north or south pole
NUMERICAL MODEL - a type of mathematical simulation capable of performing complex predictions

OCEAN CIRCULATION - the movement of water in the ocean basins and a key regulator of climate

PALAEOCLIMATOLOGY - the study of the Earth's past climate, used to understand modern climate change

PARIS AGREEMENT - a landmark international treaty, effective from 2016, that sets out a global framework for avoiding dangerous climate change

RUNOFF - the draining of water from land into a larger water body (e.g. the ocean)
"The ultimate goal of my research is to determine what causes the Earth's climate to change abruptly," says climate modeller Dr Alan Condron. "To do this, I use numerical models to determine what factors drove changes in climate, tens to hundreds of thousands of years ago." Extreme and rapid climatic changes have happened in the past, with profound impacts for life on Earth, and it is very possible these could happen again - and are potentially already happening. "Dramatic shifts in global temperatures or rainfall patterns would directly affect human society," says Alan.

The Earth's climate is a dazzlingly complex system and predicting how it will change is no easy task. There is a huge array of factors to consider: not only greenhouse gas emissions, but many other variables such as deforestation, ocean chemistry and melting ice, to name a few. Alan is currently focusing on one particular factor. "A key part of my research focuses on determining whether changes in freshwater runoff from melting ice sheets near the Earth's poles could trigger abrupt shifts in climate," he says.

FROM ONE POLE.

At present, Europe benefits from the Gulf Stream, a flow of warm water from the tropics of the Americas, across the North Atlantic and to the shores of western Europe. The current warms the air above it, which is why parts of Europe 
Alan's work has a significant role to play in anticipating, and responding to, possible future scenarios for the world's climate. $\mathrm{He}$ explains how he makes these predictions and why they are important for society.

\section{WHAT ARE CLIMATE MODELS?}

A climate model can be as simple as a one-line equation that calculates average temperature on Earth by incorporating estimates of how much energy from the Sun is absorbed or reflected into space. However, more precise models are far more complex, going so far as three-dimensional 'Earth systems' that comprise countless lines of computer code and incorporate many different climatic processes. The level of complexity needed depends on what questions need to be answered.

\section{HOW LONG DOES IT TAKE TO CREATE} A CLIMATE MODEL?

It depends on its complexity. Simple models can be created in a few hours, but complex models can take several years. These models are so complex and contain so many different components of the climate system, that they are usually developed at dedicated modelling centres by a full team of programmers and climatologists.

\section{WHAT ARE THE BENEFITS OF CLIMATE MODELS?}

Climate models are the only way we can predict future climate change. For instance, they are used by the UN and governments around the world to calculate how much we need to reduce greenhouse gas emissions to achieve the Paris Agreement's goal of limiting temperature rise to $2^{\circ} \mathrm{C}$.

\section{WHAT ARE THE LIMITATIONS OF}

CLIMATE MODELS?

All models are simplifications of the real world. In the real climate system, there are many processes that are either too complex or not understood well enough to fully simulate. If the model does not accurately describe a component of the climate system, predictions may deviate from what the real outcome would be. Right now, we are working to make models as accurate and close to reality as possible.

\section{WHO USES CLIMATE MODELS?}

Historically, climate modelling was the realm of just a few specialists. These days, they are run by glaciologists, geologists, palaeoclimatologists and biologists - to name just a few. With the advent of the internet and easily accessible high-powered computers, anyone with a laptop can download and run many useful and informative climate models.

\section{HOW TO BECOME A CLIMTE MODELIER}

- There are many pathways towards climate modelling, but Alan recommends getting a degree in mathematics, physics or computer science, "although an interest in computer programming and Earth Sciences (geography, geology) would also get you a long way. There is no

$$
\text { magic formula!" }
$$

\section{According to QS World University Rankings, the} best universities for mathematics or physics are MIT, Harvard, Stanford, Cambridge and Oxford. Alan says, "There are also many other great universities out there, where you can get the same education but that don't require you to have 'top grades'. In fact, if you've got commitment all you need is to join a local library and read books on these subjects."

- A number of institutes specialise in climate modelling and often offer internships for students or postgraduate positions. In the UK, Alan suggests looking into research institutes such as ECMWF at Reading University, the Met Office and National Oceanography Centre,

Southampton. In the US, he recommends the Los

Alamos National Lab, National Center for Atmospheric

Research (NCAR), Princeton and MIT. If you are also interested in studying 'past climate change', the universities of Leeds, Bristol and Sheffield (UK) and the University of Massachusetts Amherst, Brown University and Columbia/Lamont (USA) are great places to look.

\section{MXXNA $12 x \cdot$}

\section{ALAN'S TOP TIPS}

8

01 If you're considering climate modelling, make sure you enjoy coding! Start by learning to write code for something you're interested in - maybe a simple computer game you can test on your friends. And there are lots of programming languages that are free to use.

02 There are many pathways to become a climate modeller - from backgrounds in computer science, physics or Earth sciences, to name a few.

- According to Glassdoor, the average salary for a climate scientist in the US is around $\$ 77 \mathrm{k}$. 


\section{. HOW DID ALAN BECOME
A CLIMATE MODELLER?}

WHAT DID YOU WANT TO BE WHEN YOU WERE YOUNGER?

I had no idea I wanted to be a scientist when I was a child. My dad worked in manufacturing, and even the idea of going to university seemed ambitious to me! I always enjoyed science at school, but I had no idea it was possible to do it as a career. I actually wanted to be either a medical doctor, computer games programmer, or outdoor instructor - quite the range!

\section{WHAT DREW YOU TO GEOLOGY AND} GEOPHYSICS?

My parents would take me and my brother on long walks in the UK's National Parks. I remember standing on mountains thinking how cool it would be to study a degree that led to me being outside most of the time. As a result, I took up Earth Sciences at the University of Wales, Aberystwyth.

\section{HOW DID YOU GET INTO CLIMATE} MODELLING?

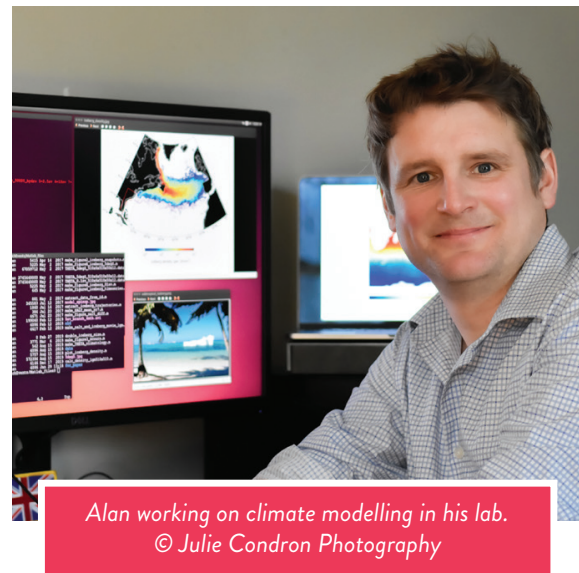

I don't come from either a computer science or physics background, so I differ from many of my peers. I was interested in programming from a fairly young age, ever since my Dad bought an Atari computer in the mid-1980s and my brother and I had a go at coding. We didn't have much success at the time, but it laid the groundwork for my future career.

It was during my undergraduate degree that I first learned about climate change. Whilst studying, I stumbled across a book on palaeoclimatology and was so struck by it that I applied to do a master's degree with the author, Ray Bradley. I was very surprised to be accepted and it was during my master's that I took my first computer modelling class. It came naturally to me - all those years of Atari paid off, it seemed! I found it amazing that these models could simulate Earth's climate, help us understand its past and even predict its future.

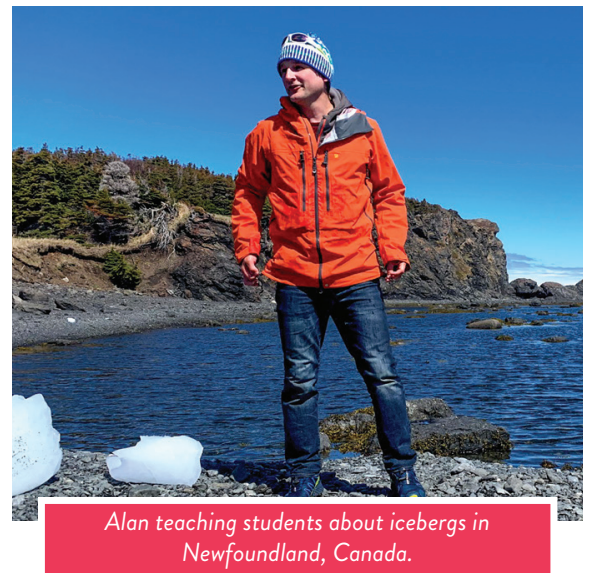

WHAT DO YOU LOVE MOST ABOUT YOUR WORK?

There is a lot of freedom in being a scientist. I can work on projects and ideas that interest and excite me, and day-to-day I am pretty much my own boss. I can also set my own hours, which means that I can stop work when I need a break or to get some exercise, and then return to the computer again later on.

\section{DO YOU THINK WE WILL SOLVE THE} CLIMATE CRISIS?

In many ways the solutions already exist, such as renewable energy technology. The hardest part is making the necessary changes at the national and international level, and there is much to be done. Small changes in our individual lives all add up too, especially if they influence others to make climateconscious decisions.

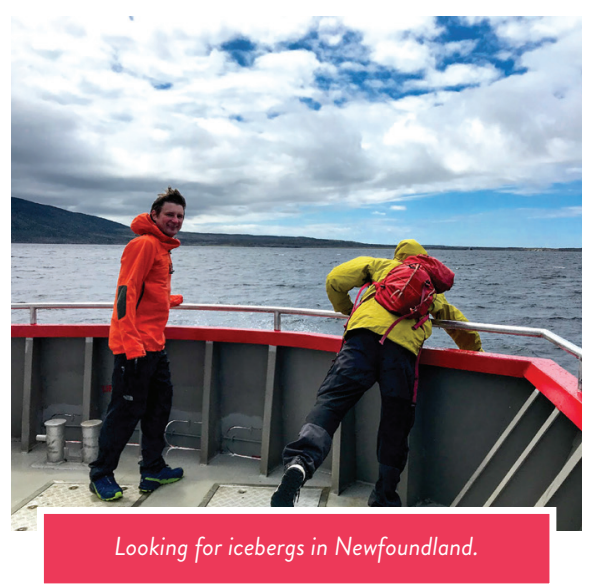

